$5-10 \%$ but was sometimes found when the level was $10-25 \%$. Though relating to a different therapeutic problem their results may be relevant. The average daily dose of $72 \mathrm{mg}$. of phenindione in this trial was less than the mean daily dose of $108 \mathrm{mg}$. used in the M.R.C. long-term anticoagulant trial (Report to Medical Research Council, 1959, 1964). The moderate anticoagulant effect might explain the low rate of haemorrhage in this trial, which is lower than that in the Danish trial or in the American Heart Association trial (Wright et al., 1948 ; Hilden et al., 1961a). The occurrence of haemorrhage in the low-dosage group in this trial was also lower than in the control group in the American Heart Association trial, so that differences in reporting levels may also be suspected.

Since this trial was designed to compare the results of allocation at an early stage of the investigation of the case, our series contained about $8 \%$ of patients in whom the diagnosis was not later confirmed, but they were equally distributed between high- and low-dosage groups. In some of these patients, and in others where complications such as haemorrhage or thromboembolism supervened, changes in treatment were made; $8 \%$ of the high-dosage group and $12 \%$ of the other group were thus affected. About $90 \%$ of the patients in each group were thus maintained on the same anticoagulant regimen throughout the 28 days of their stay in hospital.

In this trial there was a low case fatality rate $(18 \%)$ in the low-dosage group in comparison with the usual reported experience of $30 \%$ death rate in patients with myocardial infarction admitted to hospital. Possibly important was the exclusion from the trial of patients suffering, for example, from severe hypertension or giving a history of previous cerebrovascular accident. It should be noted that a small proportion of patients (see Table XIII) were admitted to the trial 48 hours or longer after the onset of the incident of infarction when the fatality rate is lower than during the first 24 to 48 hours. An important difference between this and earlier trials may lie in the major changes that have taken place in the treatment of acute myocardial infarction. Any reduction in the risk of thromboembolism attributable to earlier mobilization, for example, may well diminish the potential contribution of anticoagulant drugs to the prevention of such complications of myocardial infarction. It should be emphasized, therefore, that our conclusions relate specifically to the degree of anticoagulant effect produced in the patients selected on the criteria stipulated and in the context of the ancillary forms of treatment prevailing while this trial was in progress.

\section{REFERENCES}

Cochran, W. G. (1954). Biometrics, 10, 417.

Douglas, A. S. (1962). Anticoagulant Therapy. Oxford.

Eastman, G. L., Cook, E. T., Shinn, E. T., Dutton, R. E., and Lyons, R. H. (1957) Amer. f. med. Sci., 233, 647.

Gilchrist, A. R., and Tulloch, J. A. (1956). Scot. med. 7., 1, 1.
Hilden, T., Iversen, K., Raaschou, F., and Schwartz, M. (1961a). Lancet, 2,327

Hilden, T., Iversen, K., Raaschou, F., and Schwartz, M. (1961b). Lancet, 2, 1041 .

Honey, G. E., and Truelove, S. C. (1957). Lancet, 1, 1155, 1209.

Owren, P. A. (1959). Lancet, $2,754$.

Report to Medical Research Council (1959). Brit. med. F., 1, 803.

Report to Medical Research Council (1964). Brit. med. F., 2, 837.

Richards, R. L. (1958). Scot. med. F., 3, 235

Sevitu,

Tulloch, J. A., and Gilchrist, A. R. (1950). Brit. med. 7., 2, 965. Wright, 1. S., Marple, C. D., and Beck, D. F. (1948). f. Amer. med.

Wright, I. S., Marple, C. D., and Beck, D. F. (1954). Myocardial Infarction. New York.

\title{
Practical Approach to Management of Foetal Distress
}

\author{
T. M. COLTART, $* \ddagger$ M.B., PH.D.; N. R. A. TRICKEY, $* \ddagger$ F.R.C.S.; R. W. BEARD, †§ M.B.; M.R.C.o.G.
}

\footnotetext{
- Resident Medical Officer, Queen Charlotte's Hospital, London W.6. † Senior Lecturer, Queen Charlotte's Hospital, London W.6. ¥ Present address: Chelsea Hospital for Women, London S.W.3.

S Present address: King's College Hospital, London S.E.5.
}

$S^{\operatorname{man}}$ mary: The practical application of foetal blood which time 1,668 patients were delivered at Queen Charlotte's Hospital.

Foetal acidaemia ( $p H \mathbf{H} 7 \cdot 25$ or less) occurred in 45 of the 295 patients who showed clinical signs of foetal distress. Foetal tachycardia was the presenting sign in 33 of these 45 patients, underlining the importance of this physical sign. Foetal acidaemia in association with clinical foetal distress occurred twice as often in patients who had complications of pregnancy and who were therefore regarded as obstetrically "at risk" as it did in patients who were obstetrically " normal." No cases of acidaemia were detected in any of the foetal blood samples performed routinely on "at-risk" patients in the absence of clinical foetal distress.

\section{Introduction}

Foetal blood sampling has been proved valuable in assessment of the condition of the foetus during labour (Saling, 1965; Beard, Morris, and Clayton, 1966 ; Kubli, 1966). The clinician may, by determining the $\mathrm{pH}$ of the foetal blood, obtain a more specific index of hypoxia than the subjective evidence provided by the customary clinical signs of foetal distress. Nevertheless it is important to realize that these two methods of foetal diagnosis are complementary to one another. Alterations in the foetal heart rate and meconium in the liquor provide an indication to collect a foetal blood sample, and in return the knowledge of the foetal acid-base status provides insight into the significance of these signs.

From the practical point of view foetal blood sampling imposes an added work-load on the medical and nursing staff. In order to achieve maximum economy of effort it is essential to have a precise knowledge of the clinical conditions which are most commonly associated with foetal acidaemia during labour. This study has been undertaken to investigate which patients may benefit most from being monitored during labour by foetal blood sampling. Furthermore, an attempt has been made to describe how the knowledge of foetal $p \mathrm{H}$ has rational- 
ized the clinical management of patients presenting with an abnormal foetal heart rate or meconium in the liquor during labour.

\section{Patients and Methods}

The survey included all National Health Service patients delivered at Queen Charlotte's Hospital from 1 January to 30 June 1968.

The patients from whom foetal blood samples were collected have been classified into two groups. The first group comprised 196 patients considered to be obstetrically " normal " but who subsequently developed clinical signs of foetal distress in labour. Clinical foetal distress is defined as a foetal heart rate of more than 160 beats/minute (tachycardia) or less than 120 beats/ minute (bradycardia) and/or the appearance of meconium staining in the liquor. For the purpose of this study, when both tachycardia and bradycardia were noted in the same patient, the first sign to appear was recorded as the classifying variable. The second group of patients, referred to as obstetrically " at risk," comprised 169 patients with complications of pregnancy which are known to be associated with an increased perinatal mortality rate. A list of these conditions is shown in Table I. The procedure was to collect a foetal blood sample from all the' at-risk patients during the first stage of labour and again if possible during the second stage, irrespective of whether clinical foetal distress was present or not. If the signs of clinical foetal distress did appear in an at-risk patient during the course of labour they provided an indication to collect a further foetal blood sample even if the $\mathrm{pH}$ of the previous sample had been within normal limits.

TABle I.-Details of Complications of Pregnancy Among Obstetrically At-risk Patients

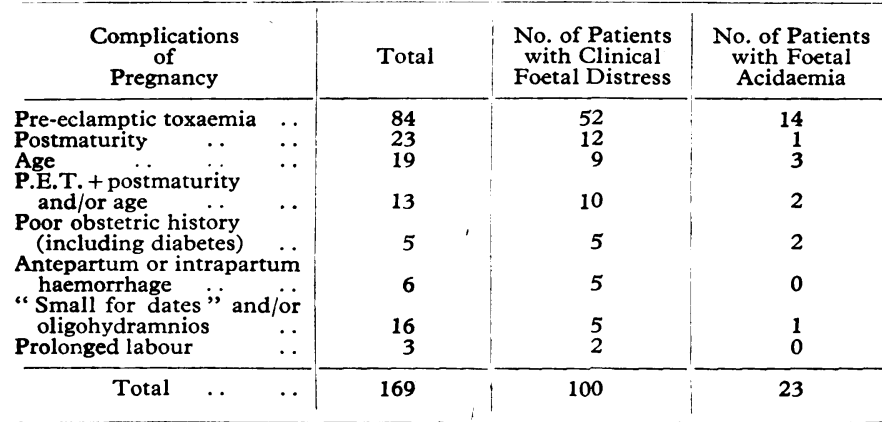

Each morning the notes of all patients delivered during the preceding 24 hours were reviewed. Details were recorded of any patient from whom a foetal blood sample had been collected. In addition details were collected of patients who should have been monitored in this way, but who for some reason were not. Routine auscultation of the foetal heart was performed during labour by a midwife, who recorded the rate on a chart at 15-minute intervals. Rupture of the membranes once labour was established was an important feature of the routine management of the labour in order to detect meconium staining of the liquor. One of six resident doctors was on duty on the labour ward throughout the 24 hours and attended all deliveries. If meconium appeared in the liquor or any abnormality of the foetal heart was reported the patient was transferred to a delivery room, where a foetal blood sample was collected and the $\mathrm{pH}$ determined by the doctor on duty. If foetal acidaemia was detected or the foetal heart remained abnormal a further foetal blood sample was collected. Foetal acidaemia is defined as a $\mathrm{pH}$ of 7.25 or less in the first stage and of 7.20 or less in the second stage of labour (Saling, 1966).

At the time of obtaining a foetal blood sample maternal venous blood was collected for the estimation of $\mathrm{pH}$. If a low foetal $\mathrm{pH}$ was thought to be secondary to maternal acidaemia, the foetal and maternal blood samples were "equilibrated" to determine the base-deficit values. The difference between the two values provided a means of assessing whether the foetal acidaemia was derived from the mother or was due to foetal hypoxia (Beard et al., 1967). However, as equilibration is a time-consuming procedure it was frequently not performed, and for this reason maternal results have not been included in the final analysis.

The decision of when a baby should be delivered rarely depended solely on the finding of foetal acidaemia, but also on such factors as the severity of the acidaemia, the clinical signs of foetal distress, and the progress of the labour. The condition of all babies at birth was assessed by means of the Apgar score at one minute and five minutes after delivery.

Perinatal mortality which can be ascribed to intrauterine hypoxia has been limited by excluding babies dying as a result of congenital malformation or rhesus incompatibility (Beard, 1968a). Babies weighing less than $1,500 \mathrm{~g}$. have also been excluded.

The technique used for the collection of foetal blood was essentially that described by Morris and Beard (1965). Modifications included the introduction of commercially heparinized glass capillary tubes instead of polyethylene tubing for the collection of blood, and the use of a specially manufactured blade for incision of the foetal scalp. The Astrup microelectrode and meter was used for all $\mathrm{pH}$ determinations.

In all, 523 foetal blood samples were collected from 366 patients during the period of the survey. Of these patients, $84 \%$ were sampled in the first stage only, $8 \%$ in the second stage only, and $8 \%$ in both stages of labour. Samples were not collected from 17 patients in whom the procedure was indicated, giving a failure rate of $4 \%$. The reasons for this included problems such as the technical difficulties encountered in collecting foetal blood, shortage of medical staff when the labour ward was busy, and the failure by both nursing and medical personnel to recognize that a pregnancy had features which placed the patient in the at-risk group.

\section{Results}

During the period of survey the 1,668 patients were delivered, and of these $169(10 \%)$ were considered to be obstetrically at risk and 1,499 (90\%) were classified as obstetrically normal

Obstetrically Normal Patients.-Clinical foetal distress developed during labour in $195(13 \%)$ of patients who, before this, were thought to be obstetrically normal. Foetal acidaemia was detected in $22(11 \%)$ of these patients, an incidence of $1.5 \%$ among all obstetrically normal patients.

Obstetrically At-risk Patients.-Clinical foetal distress developed during labour in 100 of the 169 at-risk patients, an incidence of $59 \%$ (Table I). Foetal acidaemia was observed in 23 patients $(23 \%)$ with clinical foetal distress. Of the 69 patients who progressed through labour without developing clinical foetal distress, the $p \mathrm{H}$ of all 87 foetal blood samples collected remained within normal limits. Among the 100 patients who developed clinical foetal distress 40 had one of the signs early in labour, either on admission or before an attempt would normally be made to collect a foetal blood sample. A routine sample was collected from 28 of the remaining 60 at-risk patients before clinical foetal distress appeared. In one instance there was conclusive evidence that foetal acidaemia was present before the onset of clinical foetal distress, while in a further two patients clinical signs were noted within a few minutes of detecting foetal acidaemia.

Clinical Foetal Distress.-The incidence of foetal acidaemia relative to the clinical signs of foetal distress is given in Table II. The Chart shows the distribution of $\mathrm{pH}$ values of individual cases of foetal acidaemia. Among the 295 patients with clinical signs there were 45 cases $(15 \%)$ of acidaemia. In 26 of them 


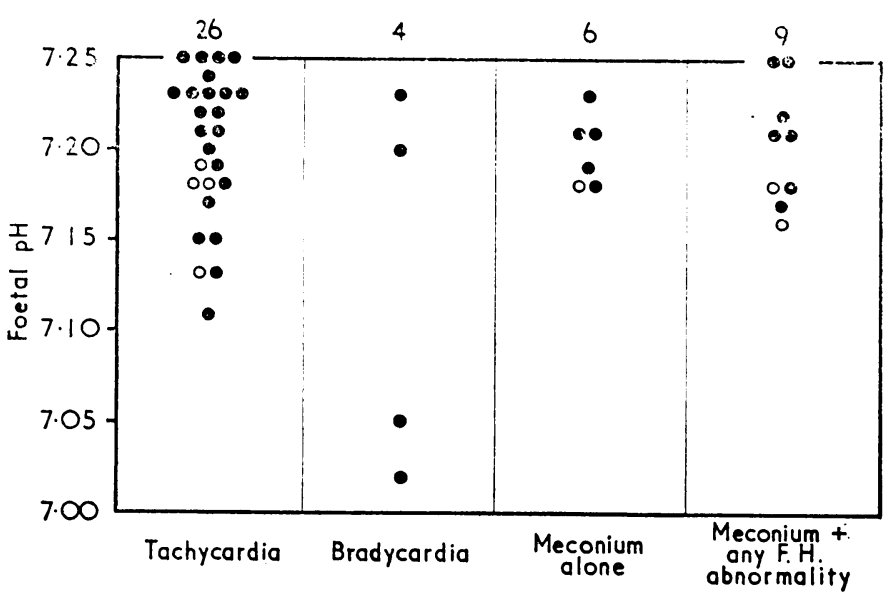

Distribution of $\mathrm{pH}$ values of the 45 cases of foetal acidaemia relative to the absociated signs of foetal distress. $\theta=$ First stage value. $O=$ Second stage value.

tachycardia was the only sign of clinical foetal distress. Further inspection of the data showed that out of the nine foetuses with meconium in addition to some abnormality of the foetal heart rate seven presented with tachycardia. There was a higher incidence of acidaemia $(20 \%)$ among cases presenting with tachycardia than among cases with bradycardia $(7 \%)$. Though the numbers are small, the difference is significant $(z=2.52$, $\mathbf{P}<0.02)$. Table II shows that if clinical foetal distress patients were considered under obstetrically normal and at-risk beadings the incidence of acidaemia in the at-risk group $(23 \%)$ was twice that in the normal group $(11 \%)$, a difference that is significant $(z=2.65, P<0.01)$.

TABLE II.-Distribution of Abnormalities of Foetal Heart Rate and Meconium in Liquor Related to Incidence of Foetal Acidaemia Among Obstetrically Normal and At-risk Patients Presenting with Clinical Foetal Distress

\begin{tabular}{|c|c|c|c|c|c|c|}
\hline & \multicolumn{2}{|c|}{$\begin{array}{l}\text { Obstetrically } \\
\text { Normal Patients }\end{array}$} & \multicolumn{2}{|c|}{$\begin{array}{c}\text { Obstetrically } \\
\text { At-risk Patients }\end{array}$} & \multicolumn{2}{|c|}{$\begin{array}{c}\text { Combined } \\
\text { Obstetrically } \\
\text { Normal and } \\
\text { At-risk Patients }\end{array}$} \\
\hline & $\begin{array}{c}\text { Clinical } \\
\text { Foetal } \\
\text { Distress }\end{array}$ & $\begin{array}{c}\text { No. } \\
\text { with } \\
\text { Acidaemia }\end{array}$ & $\begin{array}{c}\text { Clinical } \\
\text { Foetal } \\
\text { Distress }\end{array}$ & $\underset{\substack{\text { No. } \\
\text { with } \\
\text { Acidaemia }}}{c}$ & $\begin{array}{l}\text { Clinical } \\
\text { Foetal } \\
\text { Distress }\end{array}$ & 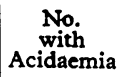 \\
\hline Foetal tachycardia & 68 & 11 & 60 & 15 & 128 & $26(20 \%)$ \\
\hline bradycardia .. & 38 & 1 & 19 & 3 & 57 & $4(7 \%))^{*}$ \\
\hline $\begin{array}{l}\text { normal F.H.R. } \\
\text { Meconium }+\end{array}$ & 58 & 5 & 9 & 1 & 67 & $6(9 \%)$ \\
\hline $\begin{array}{ll}\text { abnoormal } & \\
\text { F.H.R. } & \text {.. } \\
\end{array}$ & 31 & 5 & 12 & 4 & 43 & $9(21 \%)$ \\
\hline Total & 195 & $22(11 \%) t$ & 100 & $23(23 \%) t$ & 295 & $45(15 \%)$ \\
\hline
\end{tabular}

F.H.R. =Foetal heart rate

Difference significant $(\mathrm{z}=2.52, \mathrm{P}<0.02)$

Management of Patients with Foetal Acidaemia

Table III relates the $p H$ values of the 45 cases of foetal acidaemia to the method of delivery. The mean $p \mathrm{H}$ in group 1 was 7.17. These patients were delivered immediately after

TABLB III.-Management of Labour Following Detection of Foetal Acidaemia. Group 1 (First Stage $p H$ ) and Group 4 (second Stage $p H$ )Immediate Delivery. Group 2-Delivery Influenced by Finding of Foetal Acidaemia Earlier in First Stage. Group 3-Delivery Uninfluenced by Finding of Foetal Acidaemia Earlier in First Stage

\begin{tabular}{|c|c|c|c|c|c|}
\hline \multirow{2}{*}{ Group } & \multirow{2}{*}{$\begin{array}{l}\text { No. of } \\
\text { Cases }\end{array}$} & \multirow{2}{*}{$\begin{array}{l}\text { Mean } p^{H} \\
( \pm 2 \text { S.D. }\end{array}$} & \multicolumn{3}{|c|}{ Mode of Delivery } \\
\hline & & & $\begin{array}{c}\text { Caesarean } \\
\text { Section } \\
\end{array}$ & Forceps* & Spontaneousf \\
\hline $\begin{array}{l}1 \\
2 \\
3 \\
4\end{array}$ & $\begin{array}{r}17 \\
12 \\
8 \\
8\end{array}$ & $\begin{array}{l}7 \cdot 17 \pm 0.12 \\
7 \cdot 22 \pm 0.05 \\
7 \cdot 23 \pm 0.05 \\
7 \cdot 17 \pm 0.05\end{array}$ & $\frac{11}{3}$ & $\begin{array}{l}5 \\
\frac{9}{5}\end{array}$ & $\begin{array}{l}\frac{1}{8} \\
3\end{array}$ \\
\hline
\end{tabular}

Includes breech extraction.
$\dagger$ collection of the foetal blood sample. Eleven of the 17 patients in this group underwent caesarean section, but in the remaining six dilatation of the cervix was sufficient at the time the foetal blood sample was collected to permit delivery by forceps or vacuum extractor. Group 4 patients were comparable to those in group 1, except that group 4 patients were already in the second stage of labour when the foetal blood sample was collected.

Group 2 patients had a mean first stage foetal blood sample value of 7.22 and a foetal blood-sample/delivery time interval which varied between 2 and 24 hours. Labour was allowed to continue in these after the detection of acidaemia because the foetal $p \mathrm{H}$ was only just within the abnormal range. The subsequent management of these patients during labour, all of whom were delivered by caesarean section or forceps, was dictated either by the persistence of foetal acidaemia or by the appearance of some additional complication of labour.

In group 3 patients the mean $p \mathrm{H}$ was $7 \cdot 23$. Because the $p H$ showed no decline, and in some cases actually improved, labour was allowed to continue to a normal delivery.

\section{Apgar Score}

Table IV shows the distribution of Apgar scores among the 295 babies with clinical foetal distress. Fifty-eight per cent. of babies with foetal acidaemia had an Apgar score of 6 or less at one minute, in contrast to $24 \%$ of babies with a normal foetal $\mathrm{pH}$.

TABLE IV.-Distribution of Apgar Scores Relative to Presence or Absence of Foetal Acidaemia Among All Cases Arising with Clinical Foetal Distres

\begin{tabular}{c|c|c}
\hline $\begin{array}{c}\text { Apgar Score at } \\
\text { One Minute }\end{array}$ & $\begin{array}{c}\text { Normal } \\
\text { Foetal } \mathrm{pH}\end{array}$ & $\begin{array}{c}\text { Foetal } \\
\text { Acidaemia }\end{array}$ \\
\hline $7-10$ & $191(76 \%)$ & $19(42 \%)$ \\
$4-6$ & $37(15 \%)$ & $12(27 \%)$ \\
$1-3$ & $22(9 \%)$ & $14(31 \%)$ \\
\hline Total & $250(100 \%)$ & $45(100 \%)$ \\
\hline
\end{tabular}

\section{Perinatal Mortality}

During the period of survey there were 18 neonatal deaths and 17 stillbirths-a perinatal mortality rate of 21.0 per 1,000 births. When these figures are analysed as described under "Patients and Methods" there were five neonatal deaths and eight stillbirths. In none of the neonates did it seem likely that intrapartum hypoxia was a contributory factor leading to death, four babies having died from hyaline membrane disease associated with extreme prematurity (31-33 weeks), and one from Clostridium welchii septicaemia.

There were eight intrapartum stillbirths. These can be divided into four cases in which death was due to an obstetric accident (prolapsed cord, accidental antepartum haemorrhage, ruptured uterus, and laceration of the tentorium cerebelli), one to intrauterine infection, and three deaths with evidence of placental insufficiency which we describe in detail.

Case 1.-A para-1 whose previous pregnancy was complicated by a stillbirth showing evidence of dysmaturity. This pregnancy was uncomplicated when she was admitted in labour at 38 weeks' gestation. The foetal heart rate was regular at 130 beats/minute until it suddenly disappeared at full dilatation. A note had previously been made by the resident doctor that a foetal blood sample was not collected because the patient was " doing well." A fresh stillborn child, weight $2,295 \mathrm{~g}$., and a placenta weighing $415 \mathrm{~g}$. were delivered.

Case 2.-This patient was a primigravida with an uncomplicated pregnancy until 39 weeks' gestation. She was then admitted for observation with an unstable lie and because the baby felt "small for dates." Serial oestriol values ranged from 8 to $14 \mathrm{mg}$./ 24 hours. One week past term the patient was transferred to the labour ward in early labour. When the cervix was $5 \mathrm{~cm}$. dilated the membranes ruptured spontaneously, releasing a small amount of 
clear liquor. Five hours later the cervix was fully dilated and a footling breech presented. As the foetal heart rate was now irregular, preparations were at once made for breech extraction. Twenty minutes later, just before delivery of the baby, the foetal heart sounds disappeared and a fresh stillborn child weighing $2,420 \mathrm{~g}$. and a placenta weighing $470 \mathrm{~g}$. were delivered. No foetal blood samples were collected during labour.

Case 3.-This patient was a primigravida with an uncomplicated pregnancy. She was admitted in early labour with the membranes intact, 16 days past term. Four hours later the foetal heart rate, which had been regular, started to vary between 140 and 160 beats/ minute. Seven hours later, when the cervix was $5 \mathrm{~cm}$. dilated, the membranes were ruptured artificially, releasing thick meconiumstained liquor. A foetal blood sample collected at that time had a $\mathrm{pH}$ of $7 \cdot 15$. The $\mathrm{pH}$ of the second sample, collected 40 minutes later, was $7 \cdot 12$. A caesarean section was performed 45 minutes later. Up to the start of the operation the foetal heart rate had been between 150 and 160 beats/minute. A fresh stillborn child weighing $2,805 \mathrm{~g}$. and a placenta weighing $305 \mathrm{~g}$. were delivered.

\section{Discussion}

Clinical foetal distress occurred four times as often in foetuses at risk as it did in those of mothers who were obstetrically normal. Furthermore, once clinical foetal distress had appeared the at-risk foetus was twice as liable to develop acidaemia as was the obstetrically normal. These figures, when compiled, indicate that the chance of an at-risk foetus developing acidaemia is eight times greater than for a normal foetus.

No case of foetal acidaemia was recorded among the 69 obstetrically at-risk patients in whom the liquor remained clear and the foetal heart rate was within normal limits. This observation, though of significance, does not preclude the possibility that foetal acidaemia may occasionally precede clinical foetal distress. Wood et al. (1967b), using continuous foetal heart rate monitoring, concluded that this possibility was slight. However, it should not be forgotten that in our study foetal acidaemia definitely preceded the onset of clinical foetal distress in at least one, and possibly a further two, of the obstetrically at-risk patients. The question of whether foetal blood sampling therefore should be performed routinely on all at-risk patients in the absence of any clinical indications is at present still unanswered. It would seem that in the majority of at-risk patients it is probably sufficient to await the appearance of clinical foetal distress before collecting a foetal blood sample. The exceptions to this generalization are the small-for-dates baby that is liable to die during labour with apparently little or no warning (Cases 1 and 2) and the baby who for some other reason is considered to be particularly at risk. In these cases it is valuable to obtain serial $\mathrm{pH}$ determinations throughout labour.

The finding that foetal acidaemia was most commonly associated with foetal tachycardia is of considerable interest, since it is contrary to the commonly held view that bradycardia is the most important sign of clinical foetal distress (as exemplified by Case 3, in which intrapartum death was preceded by prolonged foetal tachycardia). In the early stages of placental insufficiency the foetus becomes hypoxic. The physiological response to this is an increase in foetal heart rate (Dawes et al., 1960). This probably raises the cardiac output, thus increasing the blood flow through the placenta while at the same time maintaining an adequate supply of oxygen to tissues which are exposed to a lowered arterial $\mathrm{Po}_{2}$. Bradycardia results if hypoxia is prolonged (Born et al., 1956), or may occur in the absence of any preceding tachycardia if the hypoxia is suffciently profound. In our study, 33 of the 45 patients with foetal acidaemia presented with tachycardia. It is not unreasonable, therefore, to propose that these babies were subjected to a shorter period of hypoxia than if labour had been allowed to continue until the appearance of bradycardia. The importance of tachycardia as a sign of foetal hypoxia has been confirmed in a study by Wood et al. (1967a) in which the foetal heart rate was recorded continuously. They found that when slowing of the foetal heart during the phase of uterine contraction was followed by tachycardia during the phase of relaxation there was a high likelihood of the baby being born with a low Apgar score.

Meconium in the absence of any foetal heart abnormality occurred in 67 patients, nearly one-quarter of all patients who developed clinical foetal distress. The incidence of foetal acidaemia in these patients, however, was low $(9 \%)$. Though this represented a smaller return than obtained among patients presenting with tachycardia, for example, the early detection of hypoxia would seem to justify the effort expended.

In general, Apgar scores tended to reflect the $\mathrm{pH}$ of the foetus. That a closer correlation was not to be found underlines the point that many factors, apart from intrapartum hypoxia, contribute towards the condition of the infant at birth (Moya and Thorndike, 1963).

The perinatal mortality rate, 21 per 1,000 births, during the period of the survey compares well with the figures in this hospital of 27.4 and $29 \cdot 3$ per 1,000 for the years 1963 and 1964 , which immediately preceded the introduction of foetal blood sampling. One factor which undoubtedly contributed towards the improvement was the decrease in the number of babies whose death might have been ascribed to intrapartum hypóxia (as defined under "Patients and Methods"). In 1963 and 196435 and 31 babies died from this cause, as compared with 19 in 1967 and 12 in the first six months of 1968. Thus it seems reasonable to conclude that the introduction of foetal blood sampling in this hospital has contributed towards an improved salvage rate of babies suffering from intrapartum hypoxia. However, it must be recognized that stillbirths due to acute accidents during labour, as exemplified by causes such as ruptured uterus, obstetric trauma, and prolapsed umbilical cord in this survey, will recur despite the introduction of improved monitoring systems. There also remains the problem of the foetus that dies from intrapartum hypoxia without providing any indication of the need to collect a foetal blood sample.

Beard (1968b) suggested that the absence of clinical foetal distress in the presence of foetal hypoxia might be observed occasionally in the small-for-dates baby. In this context it is of interest that both stillborn foetuses dying unexpectedly during the study were small for dates, with weights below the 10th percentile on the weight-gestation chart (Lubchenco et al., 1965). The reliable recognition of the small-for-dates baby during pregnancy still remains a major problem in the practice of Queen Charlotte's Hospital. It seems likely that continuous monitoring of the foetal heart rate, in addition to foetal blood sampling, would be valuable in the management of these patients during labour.

The approach adopted in the management of foetuses with acidaemia depended on the $\mathrm{pH}$ value obtained. Cases with borderline acidaemia $(7 \cdot 24-7 \cdot 25)$ were managed along clinical lines, delivery having been awaited spontaneously in most cases, or operative intervention undertaken when the clinical need arose. Moderate acidaemia $(7 \cdot 21-7 \cdot 23 \mathrm{pH})$ necessitated serial foetal blood sampling at intervals depending on the values recorded. The mode of delivery in these patients was governed by the clinical features in conjunction with the foetal $p H$ results. Each case was handled on its merits, and it is therefore meaningless to attempt any generalization with this group. In those patients with a foetal $p \mathrm{H}$ of $7 \cdot 20$ or below immediate delivery was advocated, as the foetus under these conditions was likely to be in serious danger. This point is exemplified in Case 3 in which 85 minutes elapsed between obtaining the foetal blood sample of $7 \cdot 15$ and the baby being delivered by caesarean section. The delay was due, firstly, to the time taken before the collection of a second confirmatory sample, and, secondly, to the delay in proceeding to caesarean section. As a consequence of this experience the policy of this hospital is to prepare the operating-theatre for caesarean section imme 
diately a foetal $\mathrm{pH}$ below $7 \cdot 20$ in the first stage is reported. While this is being done there is sufficient time to collect a second foetal blood sample, to confirm the first result.

Foetal acidaemia resulting from a primary acidaemia in the mother has not been investigated in this study, as there is little evidence to suggest that this additional knowledge is a major factor in influencing clinical decisions. Beard (1969a), in a study on foetal $\mathrm{pH}$ just before delivery, when maternal acidaemia is likely to be most marked, found that the incidence of foetal acidaemia originating in the mother was in the region of $10 \%$.

Some authors (Prystowsky, 1967 ; Seligman, 1968) have questioned whether acid-base and blood gas values of scalp blood resemble values in arterial blood of the foetus. The reliability of $p \mathrm{H}$ determinations made by clinicians has also been questioned. Both these points have raised the possibility that unwise clinical decisions may be made as a consequence of false-positive or false-negative values. The clinical results during the period of this survey and in the preceding three years, when foetal blood sampling was in use (Beard, 1968a), have been reassuring in this respect. It might be anticipated that a significant number of false-positive $\mathrm{pH}$ results would lead to an increase in the number of operative deliveries during labour. In fact the reverse occurred, and during the period of the survey only 12 caesarean sections were performed for foetal distress as compared with 24 during a similar period in 1964. Undoubtedly a small number of babies are born with a low Apgar score when the $\mathrm{pH}$ of the foetal blood sample and umbilical cord blood is within normal limits. It is not possible to state whether such an outcome can be considered a "false"negative result or not. However, in our experience, with the single exception of a case of intrauterine infection, on no occa- sion was clinical foetal distress followed by a stillbirth provided the foetal $p \mathrm{H}$ remained within normal limits.

We are grateful to Sister Seldon, the labour ward superintendent, and her colleagues, without whose co-operation this survey would not have been possible. We are also grateful to Miss Susan Lister for her valuable assistance in compiling the results of this survey.

\section{REFERENCES}

Beard, R. W. (1968a). Proc. roy. Soc. Med., 61, 488

Beard, R. W. (1968b). F. Obstet. Gynaec. Brit. Cwlth, 75, 1291

Beard, R. W. (1969b). Proceedings of the Symposium on the Diagnosis and Treatment of Disorder Affecting the Intrauterine Patient, Puerto and Treatment of Disorder Affecting the Intrauter

Beard, R. W., Morris, E. D., and Clayton, S. G. (1966). f. Obstet. Gynaec. Brit. Cwlth, 73, 562.

Beard, R. W., Morris, E. D., and Clayton, S. G. (1967). F. Obstet. Gynaec. Brit. Cwlth, 74, 812 .

Born, G. V. R., Dawes, G. S., and Mott, J. C. (1956). F. Physiol. (Lond.), 134, 149.

Dawes, G. S., Jacobson, H. N., Mott, J. C., and Shelley, Heather J. (1960). भ. Physiol. (Lond.), 152, 271.

Kubli, F. (1966). Fetale Gefahrenzustände und ihre Diagnose, p. 793. Stuttgart.

Lubchenco, L. O., Hansman, C., Dressler, M., and Boyd, E. (1963). Pediatrics, 32, 793.

Morris, E. D., and Beard, R. W. (1965). F. Obstet. Gynaec. Brit. Cwlth, $72,489$.

Moya, F., and Thurndike, V. (1963). Clin. Pharmacol., 4, 628

Prystowsky, H. (1967). Amer. F. Obstet. Gynec., 99, 753.

Saling, E. (1965). 7. int. Fed. Gynaec. Obstet., 3, 100.

Saling, E. (1966). 'Das Kind im Bereich der Geburtshilfe, p. 124 Stuttgart.

Seligman, S. A. (1968). Proc. roy. Soc. Med., 61, 491.

Wood, C., Ferguson, R., Leton, J., Newman, W., and Walker, A. (1967a). Amer. F. Obstet. Gynec., 98, 62

Wood, C., Lumley, J., and Renou, P. (1967b). F. Obstet. Gynaec. Brit. Cwlth, 74, 823 .

\title{
Foetal Blood Sampling in the Regional Hospital
}

\author{
MOHINI A. GARUD,* M.D., D.G.o., M.R.c.o.g.; DAVID P. L. MAY,* F.R.C.S.ED., D OBST.R.C.o.G. \\ STANLEY C. SIMMONS, $\dagger$ F.R.C.S., M.R.C.o.G.
}

Brit. med. F., 1969, 1, 346-348

Cummary : Several difficulties arise in the introduction $\checkmark$ of foetal blood sampling in a regional hospital. Ideally there should be a unit sufficient to provide continuous registrar cover (anaesthetic cover and medical cover) of the labour suite. In our hospital duties have been reallocated in an attempt to attain this standard. Both consultant and registrar staff must take adequate study leave to understand the principle and practice of blood sampling. Regular lectures and demonstrations must be given to nursing and resident staff. The cost of the initial equipment is abut $£ 1,000$. $\neq$

Foetal blood sampling has been employed in the unit since January 1968. Its principal use has been the assessment of "foetal distress." Except for one case no low $\mathrm{pH}$ value has been found in a " high risk" patient unless the foetus showed signs of clinical distress.

- Registrar, Windsor and Slough Obstetric Unit, Upton Hospital, Slough. † Consultant, Windsor and Slough Obstetric Unit, Upton Hospital,

₹ The Radiometer $\mathrm{pH}$ Electrode meter and water-bath alone can now be purchased for about $£ 180$. The total cost with instruments is therefore $£ 350$.

\section{Introduction}

James et al. (1958) pointed out that neonatal acid-base measurements were reliable criteria in assessing the degree of asphyxia. Saling (1962) described the technique of foetal blood sampling and used the $p \mathrm{H}$ value obtained as a guide to the well-being of the foetus during labour.

The introduction of foetal blood sampling into the regional hospital has many difficulties. This paper describes these problems and assesses the value of this technique, which has been in use in this unit since January 1968.

\section{Materials and Methods}

Unit and Staff.-The Windsor and Slough Obstetrics Unit is a new unit converted from the old general hospital ; it contains 60 obstetric and 20 gynaecological beds. The obstetric labour suite has an admission suite, three progress rooms, and three modern labour theatres. A trolley bay has been converted into a clinical laboratory, and this is immediately adjacent to 